\title{
Color in films: a critical overview
}

\author{
Maria Helena Braga e Vaz da Costa*
}

\begin{abstract}
The use of color in cinema involves explanations and associations at different levels: (1) the physical, in the way that color can affect the viewer giving him/her a more or less pleasing feeling; (2) the psychological, because color can stimulate psychological responses; and (3) the aesthetic, because colors can be chosen selectively according to the effect they can produce, considering their balance, proportion and composition within the film. This article will consider these three characteristics of color and some film examples, in order to discuss about the role of color in cinema.
\end{abstract}

\section{Keywords}

Cinema. Color. Film. Aesthetics

\section{The discussion of color in the cinema}

The use of color in cinema involves associations at different levels: (1) the physical, in the way that color can affect the viewer giving him/her a more or less pleasing feeling; (2) the psychological, because color can stimulate psychological responses; and (3) the aesthetic, because colors can be chosen selectively according to the effect they can produce, considering their balance, proportion and composition within the film. This article will consider these three characteristics of color in order to discuss about the role of color in cinema.

To do this, it is, first of all, worth making clear the two main views of color. The first is that color represents an 'improvement' in realism. The second is that color can be freed from the 'shade' of realism, giving birth to a wider range of signifying possibilities. Color is then an element that can be used for distinctly non-realist purposes.

In the first view, the underlying argument is that a film, with elements such as sound and color, achieves an aura of authenticity, preserving and enhancing a sense of reality. Thus, color could be seen as just another element that could approximate cinema's likeness to reality. However, initially the intricacy of making a multiple color-

\footnotetext{
* Arquiteta (UFPE, 1986), Doutora em Estudos de Mídia (University of Sussex - Inglaterra, 2001). Professora do Departamento de Artes da Universidade Federal do Rio Grande do Norte - UFRN.
} 
scale film could not be captured quickly enough to take over from monochrome film. The colors present in early films were far from what people would call 'real colors'. Moreover, color was a new and unknown additional factor for filmmakers and could slow down the construction of the film.

Because of this and other reasons, critics of the realist ideology, such as Edward Buscombe (1978), counter the idea that the introduction of color in cinema meant an improvement in realism in at least two ways. Firstly, they point to color's incompatibility with narrative realism as a consequence of perceptual problems. Secondly, they note the non-realist uses to which color was put. As will be demonstrated later, at first color meant not an improvement in realism but an improvement in the development of an 'unrealistic cinema' and the capacity of filmmakers to express fantasy.

The ideology of realism may have been an early determining factor in motivating technological development in cinema, but clearly it was not the only need that was fulfilled through technological innovation. The analysis of the introduction of color in the cinema provides an interesting example in which the 'gain in realism' was not as straightforward as some theorists have tried to imply. On the contrary, the transition from black-and-white films to color films - initially at least - was full of non-realist aesthetic experiments. This occurred at least until the use of color for narrative realism became its dominant cinematic form.

It is worth noting that the absence of color in films, which was a fundamental divergence from nature, was not obvious until color film called attention to its absence. (Cf. the introduction of sound in cinema) The use of black-and-white stock and the consequent reduction of all colors to it very considerably modified natural colors ${ }^{1}$. Notwithstanding, black-and-white films can transmit important plot details without loss of verisimilitude. When, in a black-and-white film, there is a reference to any specific color, this is no less effective because the color cannot be seen. As Dick (1990) points out:

In Jezebel (William Wyler, 1938), a black and white film, Julie (Bette Davis) arrives at a ball in a red dress that she has been forbidden to wear. The dress photographs as non-white, and white was the color Julie was expected to wear. Juliet's (sic) act of rebellion is as effective today, when color films are the norm, as it was in 1938 when color films were-the exception (p.73).

The 'truth' is that the audience can accept the absence of color in films when other codes of narrative realism are taking place. Color thus was not the fundamental element in the spectator's judgment about whether the film was realistic or not. As Arnheim (1958) points out:

The spectator experiences no shock at finding a world in which the sky is the same color as a human face; he accepts shades of grey as the red, white, and blue of the flag; black lips as red; white hair as blonde. The leaves on a tree are as dark as a woman's mouth. In other words, not only has a multicolored world been

${ }^{1}$ Black-and-white films did not even leave natural brightness values untouched. The reds, for instance, may become too dark or too light, depending on the emulsion. (ARNHEIM, 1958) 
transmuted into a black and white world, but in the process all color values have changed their relations to one another: similarities present themselves which do not exist in the natural world; things have the same color which in reality stand either in no direct color connection at all with each other or in quite a different one (p.22).

Taking advantage of the 'so celebrated' likeness of cinema to reality, it was part of Technicolor's marketing strategy to convince the film industry that color was actually pivotal in the improvement of realism and suitable for any film. The company emphasized that the complete absence of color was unnatural. The argument was that we see real life in color, thus realist films should be in color. Natalie Kalmus, a Technicolor artistic adviser, wrote:

\begin{abstract}
'Motion pictures have been steadily tending toward more complete realism.... The advent of sound brought increased realism through the auditory sense. The last step - color, with the addition of the chromatic sensations - completed the process. Now motion pictures are able to duplicate faithfully all the auditory and visual sensations. This enhanced realism enables us to portray life and nature as it really is, and in this respect we have made definitive strides forward' (Quoted in WATTS, 1938 , p. 116).
\end{abstract}

Nevertheless, at the same time that Technicolor claimed that its product was necessary for a gain in realism it warned that its 'exaggerated' use would be unnatural. It could have an unpleasant effect upon the eye and upon the mind of the spectator causing perceptual difficulties (retinal fatigue). Early color films also faced the problem of how to be cut - i.e. edited. A minimal variation between shots could change the balance between the colors and cause perceptual disharmony. This provoked a 'movement' against the use of color in cinema.

With these 'perceptual' problems faced by early color cinematography, another point was consequently raised. An 'exaggerated' use of color, allegedly, had a disruptive effect upon perception distracting the audience's attention from essential elements of the narrative. Color then was seen to have a controversial relationship with the narrative. Evidently, this arose in part because of the short technical scale of familiarity with color's use in filmic construction. Early evidence of color's 'distractions' can be found in a comment by Douglas Fairbanks whose film The Black Pirate (Albert Parker, 1927) was produced in color:

'Not only has the process of color motion picture photography never been perfect, but there has been a grave doubt whether, even if properly developed, it could be applied without distracting more than it added to motion picture technique. The argument has been that it would tire and distract the eye, take attention from acting, and facial expression; blur and confuse the action. In short it has been felt that it would militate against the simplicity and directness which motion pictures derive from the unobtrusive black and white' (in BUSCOMBE, 1978, p. 24).

Another example of color's perceptual difficulties is identified by the scientist Cornwell-Clyne: 
'When the audience's attention is diverted from the action of the drama, or from the drama in the action, by a color incident, arrangement, or phenomenon, then such color is an intruder destroying the unity of the film and usurping the proper functioning of other more important elements of the film dynamics' (in HUNTLEY, 1949 , p. 194).

\title{
Cornwell-Clyne explained why color films caused eyestrain.
}

We have for years trained audiences to accept large out-of-focus areas, though such areas correspond to nothing experienced in normal vision, which is sharp always at the centre of vision. This has become a convention or even a stratagem of photographic technique. But a large background area in poor focus when rendered in color became curiously disagreeable, especially if it contains any parts which are relatively pure in hue (bright color), because the eye is inevitably attracted thereto and it is the reflex attempt to focus the unfocusable which is the cause of the unpleasantness. The result is eyestrain (p.197).

By contrast, in Basten's (1980) opinion, color was not an element that could distract the spectator's attention but rather attract it. As he writes:

\begin{abstract}
The eye, accustomed to the shadings of black and white, has less difficulty meeting the demands of the new element; the color is not a distraction but an attraction as valuable and little more obtrusive than the musical score (p.61).
\end{abstract}

Such imputed distractions - perceptual and consequently narrational - were not acceptable at a time when realism was the motor driving any introduction of new techniques and technological innovations in cinema. This partly explains the time lag in the exploitation of color technology regarding its full expressive potential. Here, it is clear that the time lag between color's invention and development and its widespread use occurred because people were expecting color in films to be exactly like color in nature, and early color films were, from the above perspectives, a complete failure as representations of 'real colors'. Therefore, by the 1930s the realist codes were well established in black-and-white. The audience was familiar with them. When a new element, such as color, was introduced in the cinema it required time to be assimilated.

Another argument that counters the realist use of color is the association of color with 'unrealistic' genres. Evidence of the unreality of color is found when its use is deployed in the genres of fantasy and spectacle - i.e. unrealistic genres such as cartoons, musicals, westerns, costume romances, fantasies and comedies (BUSCOMBE, 1978). However, it must be emphasized here that the use of color in these 'unrealistic' genres was not a consequence of someone's - producers, filmmakers, etc. - conscious determination to associate color with them in order, say, to find a more suitable use for an element that was causing such perceptual problems. They were still looking at color as an element that could improve the realism implicit in the cinema's images.

Stanley Cavell (1979) contradicts the idea that color makes film 'unrealistic'. He argues that its association with non-realist genres happened not merely because color in film was inaccurate or because the stories in color films were non-realist. He points 
out: "Movies in color seemed unrealistic because they were undramatic" (p.91). As will be argued later, the dramatic quality of color was one of the most important factors in its cinematic development.

As it happened, the introduction of color coincided with the great boom in the production of musicals, themselves an outcome of the introduction of sound. It is evident that there were infinite opportunities for the non-realist use of color in genres like this. It does not have to be tied to a representation of reality, past or present. This category of film, rather, is primarily in the service of visual pleasure (BUSCOMBE, 1978). Consequently color in the ear1y 1930s was an outstanding provider of "visual pleasure" central to new forms of cinematic reception, rather than an instrument in the service of realism. Color was then used in films without any function dramatic or narrational - but to give "glamour" to the image, to produce a colorful world by using pleasant and beautiful effects.

The visual pleasure so exploited and celebrated after color's introduction in cinema offered a great opportunity to explore and intensify the image, for instance, of the female body (See NEALE, 1985). In a time when the "star system" was a very important product, color served the purpose of emphasizing the looks and beauty of the "stars". As Steve Neale (1985) remarks: "...the development and description of the spectacle of color in film has been centered on the image of the female body as the focus simultaneously of nature, artifice, beauty and the look" (p.109).

With this tendency to associate color with the representation of 'the unreal', no one at that time could expect to see realist films in color. The continued use of blackand-white in features like documentaries as a guarantee of truth attests to this argument. Filmmakers, too, were concerned with color and its usage. The passage below is used by the film director John Huston to justify the use of black-and-white, rather than color, in his film Reflections in a Golden Eye (1967). He thought that because the plot of the film was basically concerned with human emotions, and thus real emotions, it would not make sense to use color in it.

Color in nature is very different from color on the screen. When you sit in a darkened theater your attention is so concentrated on the screen that the images seem more fully saturated with color than they are in reality. Thus color effects are unnaturally heightened. This kind of color has been fine for extravaganzas and spectacular films. But when we are dealing with material of psychological content it becomes invariably distracting as it gets between the viewer and the mind he is trying to search into (John Huston in BASTEN, 1980, p. 136).

An interesting fact is that filmmakers really began to exploit abundantly this non-association of color with reality. They saw color as a 'tool' that could be used by means of differentiation, as a language, between 'real world' and the 'world of dream'. Evidence of this fact can be found in feature films such as The Wizard of $\mathrm{Oz}$ (Victor Fleming, 1939). In this particular film, the use of color is restricted to the private fantasy world of Oz while the 'real' world of Dorothy's Kansas home is shot in blackand-white.

Analyzing these early uses of color (1930s to 1940s) Hollander (1989) considered the advent of color a set-back for the quality of film realism. The advance, he argues, was in the pleasure and excitement that color gave to the images, despite 
being exaggerated. The exaggerated use of color was, in his view, acceptable in cartoons or musicals but never in realist films or documentaries. Hollander even suggests that color can sometimes be a 'pure amenity', a 'modern luxury' but not a necessity, at least in order to emphasize the realism of the film images. However, his opinion is that color can also have its realist moments. Hollander (1989) then writes: "In documentary nature films...color has its own abstract 'realistic' beauty, which has very romantic overtones" (p.48). At first he is concerned with the motivation for bringing color into cinema criticizing thus color's 'distance' from realist cinema. His conclusion is based on early examples where color had been used with the clear intent of producing a 'world apart' emphasizing the 'beauty' (of the 'star' for instance) in unrealistic genres. But then he seems to recognize and to accept the 'realistic' use of color in documentary nature films. Perhaps, because nature and beauty have frequently been linked to each other he assumes that the use of color is thereby justified.

From an anti-realist standpoint, Carl Dreyer's (1955) position was that to expect color in films to be 'natural' was a misconceived approach to its potential usage. The issue of color is addressed differently. 'Art', Dreyer argued, has nothing to do with 'real colors'. Because of the difference between color in film and the colors in nature, he argues, the audience is able to have an enhanced aesthetic experience. Thus, the colors in film can be chosen to harmonize according to considerations regarding its proportion and composition within the narrative, and consequently they can generate great aesthetic effects.

Walt Disney, with his creative use of color in cartoons, appears to provide support for Dreyer's point of view. Nevertheless, the use of color in his case is still confined to an 'unrealistic' frame. However, it is worth pointing out the importance of Disney's creativity for the later aesthetic development of color. After Disney, a new status was given to color. Disney cartoons were even used as an example by $\mathrm{Dr}$. Herbert T. Kalmus, Technicolor's director general, to convince the major studios to adopt color, in spite of its being double the cost of black-and-white productions.

You have seen Disney's Fanny Bunnies; you remember the huge rainbow circling across the screen to the ground, and you remember the Funny Bunnies drawing the color of the rainbow into their paint pails and splashing the Easter eggs. You all admit that it was marvelous entertainment. Now I will ask you, how much more did it cost Mr. Disney to produce that entertainment in color than it would have in black and white? The answer is of course that it could not be done at any cost in black and white, and a similar analogy can be drawn with respect to some part of almost any Technicolor feature (Dr. Kalmus in COOTE, 1949, p. 73).

Regarding the creative use that Disney made of color Spottiswoode (1950) remarks:

The director can choose his color as freely as can the painter. Disney has already provided many examples of the subjective, non-naturalistic use of color (e.g. the babes in the wood, when the witch falls out of the sky in to a cauldron of boiling liquid, and undergoes the most entertaining changes of color in the process of cooling on the ground.) (p.152). 
In animated cartoons color has served as the 'natural medium of expression' which made it an important form of entertainment. As Turney (1940) argued very passionately, behind its unrealistic images, animated cartoons, with color and music, provide a '...great social function to a sorry world by aiding the masses through periods of distress and worry, and helping to restore a normal balance' (p.10). In his opinion cartoon audiences can escape from the '...world of obligations, necessity, and monotony...' and emerge '...into a magic, fantastic atmosphere of freedom, variety, and adventure' (p.10).

Nevertheless, regarding Walt Disney's cartoons, it is interesting to see a theorist like Kracauer drawing from their fantasy worlds a realist conclusion. Kracauer (1961) saw Disney's cartoons as an attempt to link the use of animated color with the desire to achieve realism. Kracauer explains that animated cartoons, of course, do not 'hold truth' as does a photographic film because, unlike the latter, they are pictures of 'the unreal' - of what never happens. However he identifies in cartoons increasing attempts to express fantasy in realistic terms.

From his first Mickey Mouse films to Cinderella and beyond it, Disney has drawn the impossible with a draftsman's imagination, but the draftsman in him has become more and more camera-conscious. There is a growing tendency toward camera-reality in his full-length films....It is nature once again which appears in Snow White, Bambi, and Cinderella. To intensify this impression Disney shoots his sham nature as he would the real one, with camera now panning over a huge crowd, now swooping down on a single face in it. The effects thus produced make us time and again forget that the crowd and the face in it have been devised on a drawing board (KRACAUER, 1961, p. 89-90).

It is worth noting the difficulty that some authors and theorists have in accepting color in films. They look desperately for a realist response within the use and exploitation of color. However, what they do not take into account are the aesthetic and dramatic values that color can represent within the narrative. It does not seem appropriate to say that color constituted a 'set-back' in the quality of film realism, as Hollander (1989) has argued. Realist films were continuously being made and eventually any kind of other development could have arisen from this experience. Moreover, at a later stage, the use of color proved to be acceptable within realist genres. Rather, it must be said, that the realist ideology represented an obstacle to the development of color regarding its dramatic and narrational capabilities. If people were not so 'obsessed' with making and seeing the cinema as 'the mirror of life' perhaps the potential of color and its use would have been realized before they actually were. 


\title{
Color as a Potential Resource
}

The issue not addressed by realist advocates of color or those demanding its integrative function is that of why color, or another signifying element, cannot be detached from the other elements in the narrative assuming an independent position in films? Why are many historians and critics reluctant to consider other functions for color than to those which strictly serve to improve realism? The value of color in films lies in the fact that it is a 'natural element of visual reality' and permits 'artistic effects' (NEALE, 1985). Color can be used to give visual pleasure, an element that can be deliberately manipulated. It can be used expressively, according to which colors are chosen, how they are arranged and mixed to emphasize dramatic effects. Color can also constitute a significant element of the narrative. Gradual modifications in the color of a scene as well as changes in costume and setting can assume different significances.

As Branigan (1984) comments:

\begin{abstract}
The color itself, of course, may be produced in many ways: through the use of special film stock, camera filters, mise-en-scene, lighting, laboratory processing, etc. It is not the technological origin which is decisive, but rather the employment of color in a system of character narration (p.94).
\end{abstract}

For some filmmakers color could be integral to cinematic realism only if it was not separated from the narrative. Accordingly, in his study on the use of color in the cinema Bettetini (1973) analyzed the early use made of it and the problems faced by early filmmakers. He found out that the greatest difficulty experienced by the director when deciding whether or not to use color was the '...impossibility of a thorough and secure control of chromatic combinations' (p.121). For him the tonality and intensity that a certain color assumed when printed on film was one of the problems faced by the directors.

Bettetini (1973) is aware of the fact that new technologies made it possible to reduce the accentuated difference between the colors of reality and those of the filmed image. Even so, he continually worried about the great distance that separated film from reality. Bettetini's (1973) interest in this matter drove him to associate the use of color with realism, and consequently his suggestion was that a 'chromatic equilibrium' should be reached in order '...to establish an adequate point of reference for the action itself' (p.121).

In Bettetini's (1973) view, because color is an element that conditions the entire narrative (with its different use in different shots), it must be used carefully, without any exaggerated application. Thus, he attributes to color a 'simple integrative function', that is, every exaggerated use of it should be avoided. Bettetini points out that while color does not bring the images '....into a perfect and impersonal conformity with the forms of nature...'(p.125) it should not be used in realist films, which are in his view '...a tendency which is to some degree latent in the entire history of the cinema and which the film industry still presses for' (p.125). However, Bettetini is assuming that the function of the film is to produce a 'unified aesthetic experience'. 
Another interesting point to be made is related to Arnheim's (1933) statements regarding cinema and art. In his study he compares the creative work of the painter with creative work in the cinema. Arnheim argues that a painter creates colors afresh on his palette. The painter is then able to choose appropriate tones and the way that masses of color will be distributed. As Arnheim explains, the painter tries '...to get as far away from nature as is necessary to convey his artistic intention' (p.77).

Making analogies between painting and cinema, it could be said that films are the product of an artist (the filmmaker) and thus the elements and techniques used in films are manipulated. So, even if the splendor of color in painting is said to be full of choices - and in film this choice cannot be exercised to its full extent - why cannot the colors in film be used as creatively as they are in painting (SPOTTISWOODE, 1950)?

But Arnheim (1933) seemed to think - and his view was certainly influenced by the prevailing codes of cinematic realism of his time - that a creative and free use of color would be impossible. For him the free use of color would result in the mistake of dissociating the film image from reality.

\begin{abstract}
'...black-and-white has for many years been a recognized and most effective medium. The reduction of actual color values to a one-dimensional grey series (ranging from pure white to dead black) is a welcome divergence from nature that renders possible making of decorative pictures rich in intellectual significance by means of light and shade' (ARNHEIM, 1933, p. 77).
\end{abstract}

However, later Arnheim states:

'Film is the art that approaches most nearly to reality - if by reality we understand the sum total of what our eyes and ears tell us.... A film image shows us the world exactly as we see it. Whatever the camera reproduces is reality, the most exact reality' (ARNHEIM, 1933, p. 160).

Arnheim's position is indeed contradictory. In the first passage he confirms the black-and-white acceptance by the audience as realistic. Then in the second passage he states that film represents the world exactly as it is. But the world is in color. It is worth noting this 'blind spot' in Arnheim's interpretation because it accounts for the inherent contradictions of any realist purism.

Rouben Mamoulian (1935) predicted the - highly predictable - widespread substitution of black-and-white by color films. With this in mind, the relationship between realism and color became his central concern. However, in contrast to some filmmakers' and theorists' position, his view was that color could be used realistically. It could be used within the narrative structure to intensify the dramatic effect within some scenes. Mamoulian argued for an 'emotional realism'. He believed that the only danger in the adoption of color would be its 'excessive' use, as did many before him (e.g. BETTETINI). He pointed out the 'excessive' dialogue that had accompanied talking pictures. The same, he asserted, could occur with an injudicious use of color. Mamoulian (1935) writes: 'Colour should not mean gaudiness. Restraint and selectiveness is the essence of art' (p.226). Nevertheless, the notion of 'excess' should be interpreted in the context of the period upon which statements such as Mamoulian's were based. It follows that as long as the aesthetic qualities of colors became known 
and its use made easier, this 'excess' became somewhat 'natural'. In melodrama, for instance, color is used to excess, but it is accepted within the genre.

It must be noted, however, that, as time went by, and color's creative use for dramatic purposes came to be evident, Mamoulian (1960) reviewed of his early statements. He asserted that '...it is the psychological and dramatic of colour that becomes of paramount importance' (p.71). He even argues that:

'The film maker should never allow himself to be strapped by naturalism in treating with colour values. All sorts of creative departures, even to radical extremes, should be practised on the screen, the deciding factor being not - "is this the way it is in life?," but "is this the best way to express the desired emotions?" (p. 74).

An example of this is the 'effective atmosphere' created by the use of color in the ballroom sequence in Becky Sharp (Rouben Mamoulian, 1935) which was the first feature film made using Technicolor's three-color process. The scene in question is built up through a series of shots in which the colors 'flow' in a sequence from cool and sober colors to more 'exciting' colors like orange and red. This effect is achieved through the selection of the colors of the dresses and uniforms worn by the characters. In his description of the scene, Mamoulian (1960) points out the importance of his decision to use color in order to produce an 'emotional climax', therefore he was aware of the 'unreality' of his decision. However, the realism of the images, taking the endresult intended into account, was not compromised. Mamoulian (1960) gives this description:

'A ball is given in Brussels on the eve of Waterloo, at which Wellington, his officers, and hundreds of civilians are present. A messenger secretly informs Wellington that Napoleon is on the march towards the city. Wellington gives an order which is delivered confidentially to all the officers present. Following this, the news leaks out and starts a panic among the guests. They begin to flee as fast as they can. Now, in terms of realism, the officers, who heard the news first and had an immediate duty to perform, would certainly leave the building first. Yet, visually, color-wise, it would have been wrong. All British uniforms of the period were red. Were I to show these in first shots and then follow them with less striking, mingled colours of the civilians, I would be decidedly building towards a chromatic anti-climax. So I went against plausibility and reason, and based this montage purely on color - dynamics, believing that the rising excitement of just the colours themselves would affect the audience more strongly than a realistic procedure. I divided all guests into groups according to the hues of their costumes and photographed them, as they were running away, in separate shots; this, in the order of colours in the spectrum, ranging from cold to warm. This resulted in the officers leaving the building last, instead of first. But the colour montage, from purples and dark blues to oranges and reds, achieved its emotional purpose of building up to the climax of the officers' scarlet capes in flight' (p.74-75).

Evidently, the 'value' of Becky Sharp lies in the fact that it was the first film in which the creative use of color most effectively showed its 'links with unreality'. After Becky Sharp the film industry increasingly recognized the 'new color' as an element that could become an integral part of the motion picture medium. (Cf. JACOBS, 1970)

The famous Soviet film director Sergei Eisenstein (1976) considered color 'a dramatic factor' and as such it had to be used only when necessary. Color, in Eisenstein's opinion, had to be fundamental for the development of the action. He 
points out that color functions '...as a vehicle for a certain dramaturgically unique moment' (p.383). Eisenstein makes clear his position. He does not accept that color should be used only as 'one more element' to be added to the cinema image. Color, like any other 'montage' element or technique, must be used for a specific purpose. It must have a 'function' within the narrative structure.

A good example of the use of color for dramatic purposes is given in Black Narcissus (Michael Powell, 1947). In the sequence in which a nun has decided to leave the church, she appears at first in a nun's black costume and without any make-up. The next time she appears, she abruptly opens the door and there she is in a red dress with her face covered in make-up. This transformation for Mamoulian (1960) '...carried more shock to the audience that it could ever have if it were photographed in black and white...' (p.76) Again the emotional realism 'so celebrated' by Mamoulian proves to be a powerful use for color.

There are other 'expressive' uses of color to note. It can be used for instance to emphasize a specific character's 'psychological disturb'. The emotional quality of color became one of the most important effects that could arise from its use. In Alfred Hitchcock's Marnie (1964), for example, the heroine has an intense aversion to the color red, a consequence of her attempt to suppress all memory of a murder committed at the time of her childhood (DICK, 1990). The film brings us into the color structure in a very effective way. Whenever the color red appears, the character of Marnie becomes aware of it. Not only does the expression on her face denote great distress but the color red becomes the only color on the screen. With this 'artifice' Hitchcock, from the beginning, calls the attention of the spectator to the psychological significance of this specific color in the narrative.

Still, the first time Hitchcock calls attention to the significance of the color red is when, for the first time in the film, Marnie visits her mother. She sees red flowers in the vase in the living room. The aversion to the color red is unequivocally established in this scene. To reinforce the effect, Hitchcock then fills the scene with red, the color of Marnie's hallucination.

Alfred Hitchcock provides another opportunity to comment on the signifying use of color in films. In Vertigo (1958) the colors are chosen in such a way that they make a contrast between the interior (browns, oranges, yellows) and exterior scenes (greens and blues). Inside the apartments of Scottie (James Stewart) and Midge (Barbara Bel Geddes), for instance, soft browns, oranges and yellows predominate. Important points in the film are intensified by Hitchcock with the introduction of the color red. When Scottie first sees Madeleine (Kim Novak) in the restaurant, the walls are full red. Again, when Scottie takes Madeleine to his apartment after her attempted 'suicide', the orange firelight gives a strong effect to the scene. In the exterior scenes, the color green predominates. It is present in the scene in front of the art museum which Madeleine frequents and in the Redwood Forest where Madeleine goes with Scottie.

The movement of the camera from one color space to another also establishes the powerful contrast between the two distinctive 'worlds' set up in the narrative. An example is when Scottie, following Madeleine by way of gloomy passages, opens the door of a florist's shop full of bright and red flowers. As Cavell (1979) points out: 'The moment is almost comic in its display of assured virtuosity' (p.84-85). However, in the end, Hitchcock's use of color is 'turned inside out'. When in Judy's hotel 'Madeleine' appeared again, after Scottie's transformation of Judy, their embrace is illuminated by a green neon light that comes from outside the window. As Johnson (1970) points out: 
'Color helps elevate what might have been just a gimmicky melodrama into a haunting study of' obsession and illusion' (p.236) (JOHNSON, 1970; CAVELL, 1979; DICK, 1990).

After the 1960s virtually all fiction films were photographed in color. Then, only with the universal use of color in cinema did the use of black-and-white photography become an aesthetic choice. (Cf. the dramatic effect produced by silence in a sound film is a result of the domination of sound.) Similarly, the use of black-and-white film stock had significant connotations after the general use of color film. Examples of this are films such as Young Frankenstein (Mel Brooks, 1974) and Manhattan (Woody Allen, 1979) which were shot in black-and-white. The decision to shoot these films in blackand-white became a choice in order to represent 'the past', and specifically, an earlier era of the movies which both filmmakers nostalgically evoked (CF. GIANNETTI, 1982; PERKINS, 1972).

However, the representation of 'the past' by the use of black-and-white scenes does not mean that black-and-white must always represent past actions. In A Man and a Woman (Claude Lelouch, 1966) black-and-white is used for the present scenes. But when the heroine talks about her dead husband, for instance, the images of her memories are in color. Color is here used for past sequences (JOHNSON, 1970).

Another use of color is when it is inserted, as a brief passage, into a black-andwhite film. This originated at a time when color processes were not well developed and were very expensive. However, this kind of color system can be used, even today when 'the norm' is to shoot films entirely in color, to give a melodramatic or high effect. An introduction of a small passage of a colored image into a black-and-white film can amplify the value and the significance of a particular scene within the film (e.g. Rumble Fish, Francis Ford Coppola, 1983).

\section{Conclusion}

The cinema's ability to represent reality has constituted a fundamental issue in the study of cinema. The introduction of new techniques in cinema such as color, depending on the use that is made of them, are certainly able to add realism to the image. Nevertheless, they are not necessarily essential to allow the film image to be a closer representation of the world that exists in front of the camera.

It is common to think that as new developments are added to cinema, the more 'realist' it becomes. However, the transition to sound at the end of the 1920s, or color cinematography in the $1930 \mathrm{~s}$, for instance, were not perceived as having improved realism. Following this assumption, it is possible to conclude that improvements in technology and technological apparatuses were not the outstanding factor, but a condition, for the cinema's images to approximate reality. Film can reach authenticity, preserving and exalting a sense of reality without color, sound or deep-focus. It is also important to qualify the extent to which 'realism' can explain all the elements and techniques that have been introduced in cinema.

Clearly, cinema can represent the images presented in real life. For some filmmakers this is what a camera is for. But the tools and techniques used by them are part of 'reality' themselves, what makes 'reality' a form of expression. Seen in this light, the theory that posits the camera as an impartial instrument which captures the world in its 'concrete reality' is an inexact one. The realism achieved by cinema is not a 
matter only of rolling the camera. It is a matter of how to present the reality captured by the camera, and how this reality will be perceived by the spectator.

Thus, the realism achieved by film images is not only the result of the introduction, improvement or deployment of techniques but is also, in fact, the consequence of the construction of images and the production of meanings which have been incorporated into conventions of film realism.

The introduction and use of color, thus, has generated contradictory discourses. Color was first perceived as a technical resource (the product of the development of new technologies) that was supposed to reveal more of reality, representing an improvement in realism. The argument put forward to substantiate its use was its ability to represent the 'world we live in'. However, its use contradicted the early speculations. Very rarely has the use of color been justified on the grounds that it represents an addition to the cinema's multiple signifying possibilities.

Many were against the use of color at first because of its poor technical 'accuracy' which could cause perceptual problems. Then, color assumed a new meaning. Color was used to emphasize the 'unreal'. It was thus associated with some 'unreal' genres, like musicals, cartoons, adventures, etc. These genres opened a great range of possibilities for the use of color. Color revealed its potential for entertainment and decorative use, and more importantly, the aesthetic value of color became 'visible'.

Color cinematography assumed a crucial role in the narrative itself. There was a phase when filmmakers realized color's potential for dramatic and aesthetic purposes. They started to accept the idea that color could be used within realist narratives and could become an essential element to emphasize 'dramatists'. Color was here useful in the way that it could help to describe a character, or to represent a mood or emotions, to mention just a few examples. It thus became an important element of the narrative.

\section{References:}

ARNHEIM, R. Film. London: Faber \& Faber, 1933.

ARNHEIM, R. Film as Art. London: Faber \& Faber Ltd., 1958

BASTEN, F. E. Glorious Technicolor. London: A.S. Barnes, 1980.

BETTETINI, G. The Language and Technique of the Film. Paris: Mouton \& Co, 1973.

BRANIGAN, E. Point of View in the Cinema. Berlin: Mouton Publishers, 1984.

BUSCOMBE, E. Sound and Color. Jump Cut n.17, 23-25, 1978.

CAVELL, S. The World Viewed. London: Havard University Press, 1979.

COOTE, J.H. A Technician's View of the Colour Film. Penguin Film Review n.9, 73-81, 1949.

CORNWELL-CLYNE, A. Colour Cinematography. London: Chapman \& Hall, Ltd., 1951.

DICK, B. F. Anatomy of Film. New York: St. Martin's Press, 1990.

DREYER, C. Color and Color Films. Films in Review, 165-167, April 1955. 
GIANNETTI, L. Understanding Movies. New Jersey: Prentice-Hall, 1982.

HOLLANDER, A. Moving Pictures. New York: Knopf, 1989.

HUNTLEY, J. British Technicolor Films. London: Skeiton Robinson, 1949.

JACOBS, L. The Movies as Medium. New York: Farrar, Strauss \& Giroux, 1970.

JACOBS, L. The Mobility of Color (189-196). In Jacobs, 1970.

JOHNSON, W. Coming to Terms With Color (210-242). In Jacobs, 1970.

KRACAUER, S. Theory of Film. London: Oxford University Press, 1960.

KRACAUER, S. Nature of Film: the Redemption of Physical Reality. London: Dennis Dobson, 1961.

MAMOULIAN, R. Colour and Emotion. Cinema Quarterly v.3, 225-226, summer 1935.

MAMOULIAN, R. Colour and Light in Films. Film Culture v. 21, 68-79, summer 1960.

NEALE, S. Cinema and Technology: Image, Sound, Colour. London: Macmillan Education Ltd., 1985.

PERKINS, V. F. Film as Film. New York: Penguin, 1972.

SPOTTISWOODE, R. A Grammar of the Film: an Analysis of Film Technique. Berkeley: University of California Press, 1950.

WATTS, S. Behind the Screen: How Films Are Made. London: Arthur Barker Ltd., 1938.

\section{Título}

A Cor nos filmes: uma revisão crítica

\section{Resumo}

O uso da cor no cinema envolve explicações e associações sob três características: (1) física, no modo como a cor afeta o olhar; (2) psicológica, pois a cor pode estimular respostas mentais; (3) estética, porque as cores podem ser escolhidas seletivamente em acordo com o efeito que elas podem produzir, considerando sua aplicação, proporcionalidade e composição no filme. Este artigo considerará as três características descritas acima e alguns filmes no sentido de discutir sobre o papel assumido pela cor no cinema.

Palavras-chave

Cinema; cor; estética do filme.

Recebido em 05.04.2011. Aprovado em 11.07.2011. 